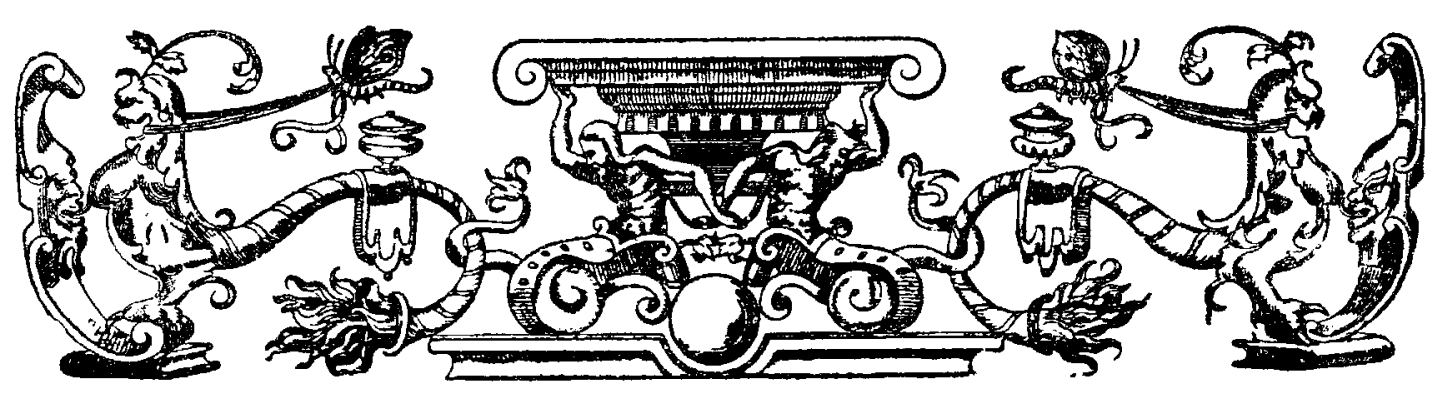

\title{
De schilder Godart Kamper
}

DOOR

DR. A. BREDIUS.

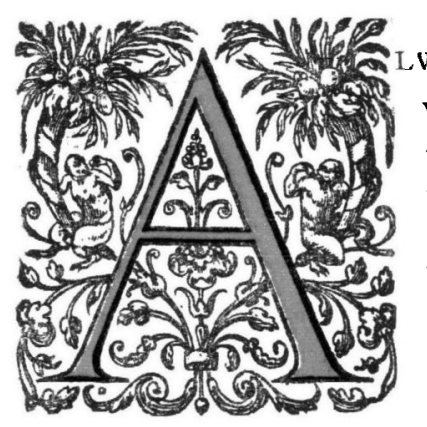

WEDER kom ik de aandacht vragen voor een bijna geheel vergeten schilder, die toch verdient, dat zijn naam weder te voorschijn gebracht wordt. Een landschap (hier afgebeeld) dat te Londen als HOBBEMa verkocht werd, zóó gemerkt was, en een flinken prijs opbracht, bleek, na herstelling, KAMPER's handteekening te dragen. Zoo iemand moet in eere hersteld worden.

Meer dan dertig jaren geleden toonde mij Generaal FABIUS, onlangs overleden, een aardig, wat donker landschapje gem. G. KAMPER f. dat hij te Naarden gekocht had. In I 889 deelde hij mij enkele bijzonderheden mede, waaruit bleek, dat KAMPER van 1668 tot 167 I te Naarden gewoond heeft. Daar het regentenstuk te Naarden echter 1663 gemerkt schijnt te zijn, is het waarschijnlijk, dat hij reeds toen of vroeger daar woonachtig was.

Vóór ik de enkele werken van onzen schilder ga beschrijven, volgen eerst de gegevens, die mij over zijn leven bekend zijn geworden.

Hij is te Düsseldorf geboren. 6 Nov. 1633 legt de I9 jarige GODART KAMPER, geboortigh van Dusseldorp, te Leiden, waar hij woonde en familie had, eene verklaring af. ${ }^{1}$ )

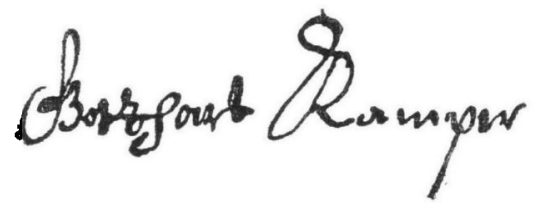

1) Prot. Not. J. J. Verwey, Leiden. 
Hij was aan het sterfbed van een kennis uit Düsseldorf, DrRCK KaldENBERGH, geweest, die aan een Luthersch koster te D. geld gelegateerd had. Wij moeten dus aannemen dat hij omstreeks 16I4 geboren is. Ik voeg hier dadelijk aan toe, dat hij te Leiden den I8en November ${ }_{1} 679$ in de Pieterskerk begraven werd als Gordertus(!) Kamper, van de Vliet.

Omstreeks 1643 was hij, ,inwoonder van Amsterdam". 28 Augustus van dat jaar heet hij aldus en zegt ,out omtrent 29 jaren” te zijn. Hij heeft daar denkelijk eerst zijn gezelschapstukken geschilderd, zooals ik er een paar in den handel zag. Een ervan, in het bezit der Heeren KRANTZ en DE BRUYN te Rotterdam, I64 1 gedateerd, vindt men hierbij afgebeeld. Men ziet den invloed van Amsterdamsche schilders als Codde, Duyster, den vroegen J. M. MOLEnaER e.a. Een ander

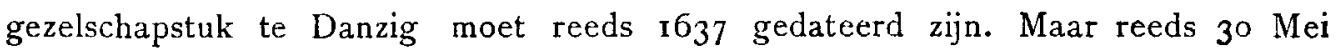
I644 huurt hij te Leiden een huis (hij woont nog te Amsterdam) aan de Oostzijde van het Rapenburg, naast Juffr. Vorstius, voor $f$ I 98 .- 's jaars. Zijn broeder, de kleermaker GERRIT KAMPER, blijft borg. 1)

I4 Januari I647 machtigen GöDERT KaMPER, Schilder, Dirck KaMPER, backer, en ADOLPHUS KAMPER, Cleermaecker, broeders, te Leiden hun broeder GERRIT KAMPER te Düsseldorf om aldaar van YSAAC YSAX, Coopman, te ontvangen roo lichte daalders, hun aangekomen van hun za: ouders. ${ }^{2}$ )

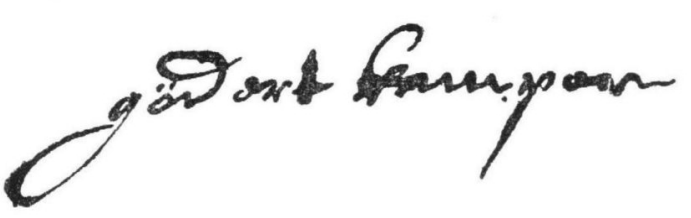

I I July s647 maken de Eersame Meester Godart Kamper, Schilder, en de eerbaere Lydia Closier, geëchte luyden, voor Not. J. J. VERwEY te Leiden hun testament. $Z_{\mathrm{ij}}$ wonen, evenals de schil-

der Joris van Schooten, op de Hooge Morsch in den Ambachte van Oegstgeest. Inderdaad vindt men zijne huwelijksaankondiging in de ondertrouwboeken van Leiden aldus opgeteekend:

I Juli r644: GODARD CAMPER, jongman van Dusseldorp wonende op de Garemardt, met Lydia Closiers jongedr, van Rochelle, wonende tot Rotterdam, is niet gecompareert, maer behoorl: attestatie overgelevert.

Bij de oprichting van het eigenlijke St. Lucas Gilde te Leiden werd GoverT(!) CAMPER I 8 Maart 1648 als een der eerste leden ingeschreven. I649- 165 I wordt zijn jaargeld vermeld; dan 1658 (misschien is verzuimd de andere jaren bij te schrijven?) waronder:

Uyt der stadt vertrocken.

1) Prot. Not. J. Scherpelingh, Leiden. Denkelijk was deze Gerrit Kamper de vader van den schilder. 20 Maart I65I maakt ADoLPH KAMPER, kleermaker, huwelijksche voorwaarden bij Not. OUTFrman, en Godert is daarbij assisteerende.

g) Prot. Not. J. van Leeuwen, Leiden. 
Dan betaalt hij weer zijn jaargeld van 1674 tot 1679 : zijn sterfjaar, toe.

Hij schijnt reeds vroeg in zeker aanzien gestaan te hebben. 22 April 1651 compareerden . . . . SR. CORNELIS CRUYS (stillevenschilder) out omtrent 29 jaren en Govert KAMPER, out omtrent 37 jaren, beyde schilders, wonende binnen Leyden, en verclaerden ten versoucke van de eersame JAN DE VOS, mede schilder 1) ende opsiender van de schilders, eerst CORN. CRUYS: dat hij op gisteren voor de middach ontbooden es geweest door seecker schilder genaemt JORDAEN [een der drie schilders JORDAENS, te Leiden werkzaam] ten huijse van SR. FLORIS MIDDELHOUCK, Coopman binnen deze Stede, omme aldaer te besichtigen seecker stuck Schildery 't welck hy deposant oordeelde en seyde gemaect te sijn bij den Ouden Heda [Willem Claesz]. . . . . (Het was aan M. verkocht voor I 2 ponden Vlaams $=72$ Gulden - door Willem Sijbrands van Amsterdam. KAMPER had het mede bezichtigd. De vraag was: of JORDAEN(S) schuld had aan het bekeuren van Willem Sijbrands door de Overlieden van het Schildersgilde. Men zeide, dat JORDAEN(S) hem bij die Overlieden aangebracht had.

Get: GODERT KAMPER.

CORNELIS KRUS ${ }^{\text {) }}$.

26 Febr. 1653 machtigt de WelEd. Heere Jor JaCOB VAN LaNTSCROON Mr. GODERT KAMPER, Schilder, om zijne zaken waartenemen. 3)

I 8 Sept. 1659 vinden wij hem terug te Amsterdam. Not. LISTINGH aldaar maakte toen de huwelijks acte op van $\mathrm{S}^{\mathrm{r}}$ GOverT (lees GoDERT) KAMPER, Wed ${ }^{\mathrm{r}}$ van Lidia Closier met Juffrouw MARgaritha SchaePS, Wed ${ }^{\circ}$ wijlen BaLthasar VAN DER VEEN woonende tot Naerden. 2o Sept. werd de ondertrouw in de boeken der Herv. Kerk te Amsterdam opgeteekend, waaruit nog blijkt dat KaMPER toen woonde bij de Halvemaensbrug.

Die bruid was de weduwe van den verdienstelijken landschapschilder omtrent wien ik indertijd een en ander in ,Oud-Holland" medegedeeld hebt. Wellicht heeft die hem aan het landschapschilderen gebracht.

In 1663 vinden wij hem te Naarden woonende. Daar was hem kort voor 23 Januari 1663 zijn tweede vrouw ontvallen. $Z_{i j}$ had hem $f$ i 2.000 . - gelegateerd, maar hare familie wilde dat bedrag niet uitbetalen. ${ }^{4}$ ) In datzelfde jaar bestelde men te Naarden bij KAMPER een zeer groot Regentenstuk voor het Burgerweeshuis,

1) Zie over hem mijne Künstler Inventare. (M. NijHoFr). Het blijkt dat deze oudere JAN DE Vos reeds in het bestuur van St. Lucas Gilde zat.

2) Prot.-Not. N. PAedT's, Leiden.

3) Prot.-Not. Tersyden, Leiden.

4) Diverse Acten daarover in de verbrande papieren van Not. IIsTrivg te Amsterdam.

Oud-Holland 1922. 
dat aldaar nog hangt in de Regentenkamer, waarvan de Heeren Regenten mij bijgaande afbeelding ter reproductie afstonden. Vijf dier Heeren, levensgroot, zijn gezeten om een tafel, waarachter, als zesde, een bode staat. De compositie is gewoon, maar de koppen $z$ ijn werkelijk goede portretten, knap geschilderd.

Hij bezocht at en toe Leiden, waar zijn vader GERRIT KAMPER thans woonde. I5 Sept. 1665 blijft iemand borg voor een student ten behoevo van den schilder voor ruim $f 35 .-$. I 2 Febr. 1673 is hij executeur van het Testament van JAN Croonenburgh te Amsterdam. 1)

In I674 overleed zijn vader GERRIT KAMPER te Leiden. Hij bezat nog al vaste goederen, maar in een request aan den Hoogen Raad vraagt de schilder om den boedel te mogen aanvaarden onder benefitie van Inventaris, daar "met dese quade tijden de huysen en vaste goederen soo veel in prijs sijn afgeslagen etc." 2 Dec. ${ }_{1} 676$ zijn GODERT en DIRCK CAMPER JR, voogden over de minderjarige kinderen van den onder benefitie van Inventaris overleden GERRIT Kamper. ${ }^{2}$ ) Daarover ontstond ruzie tusschen die twee broeders en proces.

ro Januari 1679. Monsieur Goddart Kamper, Rutgert Kamper, den E. Florentius Kamper, med. Doctor, Dirck Kamper, Notaris, Elisabeth Kamper, en FRANCHOIS DU HOPA, in huwelyck hebbende ANNA KAMPER, alle naergelaten kinderen van za: Heyltge Floris vaN ONDERWATER, in haer leven Wede en boedelhoudster van wijlen za: DIRCK KAMPER hebben een proces tegen JAN VAN ACKEREN. 3) Hier leeren wij dus de geheele familie kennen, die langzamerhand wat deftiger geworden is.

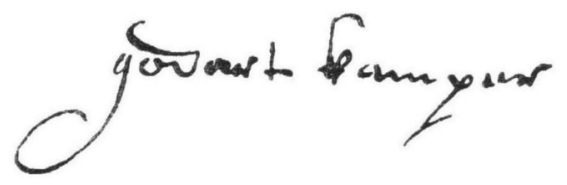

22 October 1679 voelt de schilder na een ernstige ongesteldheid zijn einde naderen. Hij maakt een lang, uitvoerig testament. Hij verklaart in den $200^{\mathrm{en}}$ penning tot $f$ 60oo.te zijn gequotiseert. $\mathrm{Nu}$ is hij de E. GODART Kamper, Constschilder, wonende op de Delftsche Vliet, sieckelyck te bedde leggende. $\mathrm{Na}$ allerlei prelegaten maakt hij tot erfgenamen de kinderen van zijn overleden broeder JAN KAMPER, de 6 nagelaten kinderen van zal ${ }^{r}$ GERRIT KAMPER, de vier nagelaten kinderen van $z^{x}{ }^{x}$ DIRCK KAMPER, het nagelaten kind van Lysbeth Kamper in haar leven huisvrouw van Philippus van Mekeres, die met FLORENTIUS en JOHANNES KAMPER executeurs en voogden worden. ${ }^{3}$ )

Het is trefiend, dat blijkbaar in dien korten tijd van eenige maanden de heele familie uitgestorven is - zonder twijfel een gevolg van een pestepidemie.

1) Prot. Not. J. Paarslaken, Amsterdam.

a) " VAN Scharpenbrant, I.eiden.

3) " " N. van LeEuwen. " 


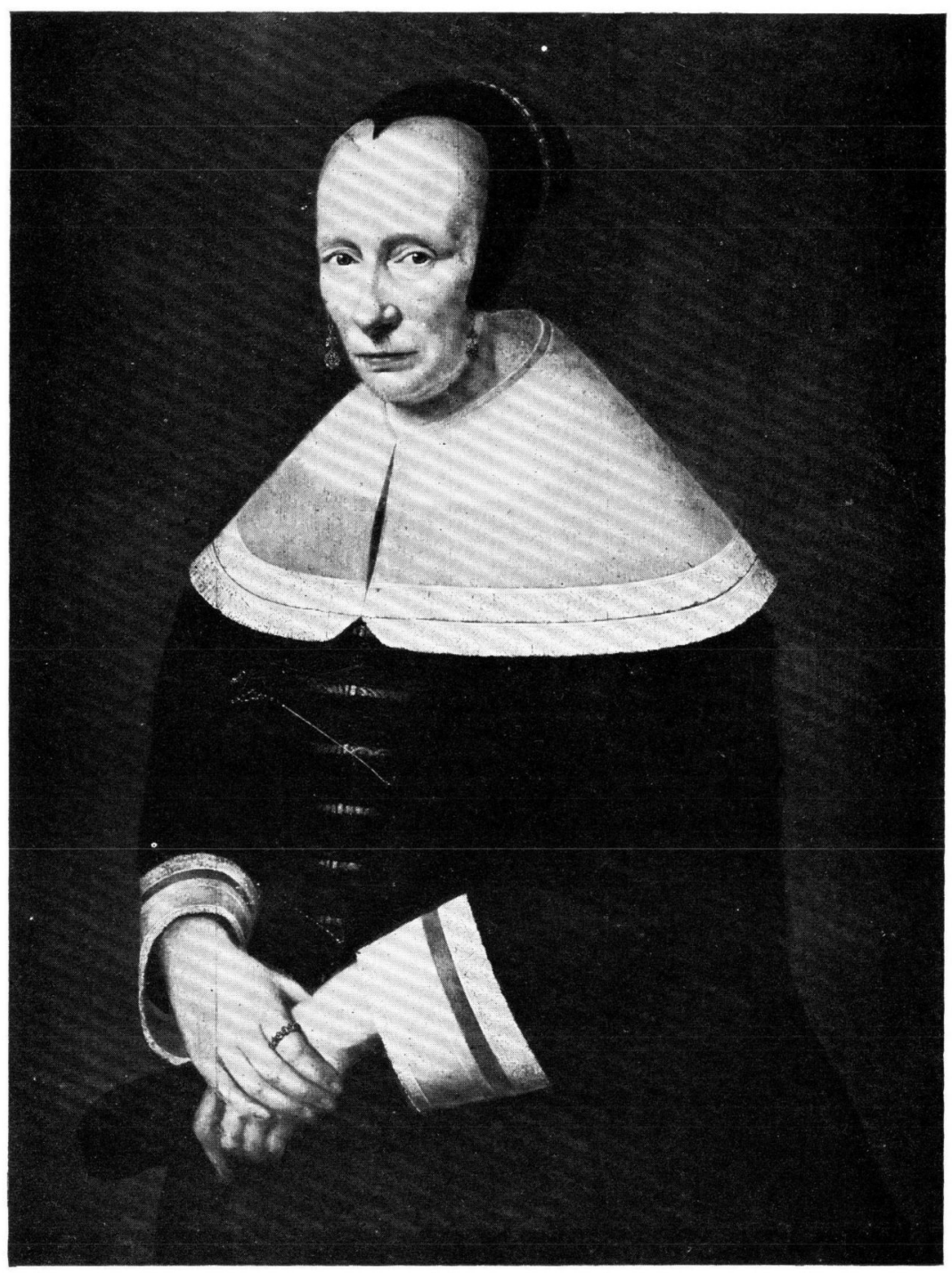

GinART Kanper. Portret.

Rijksmuseum. 


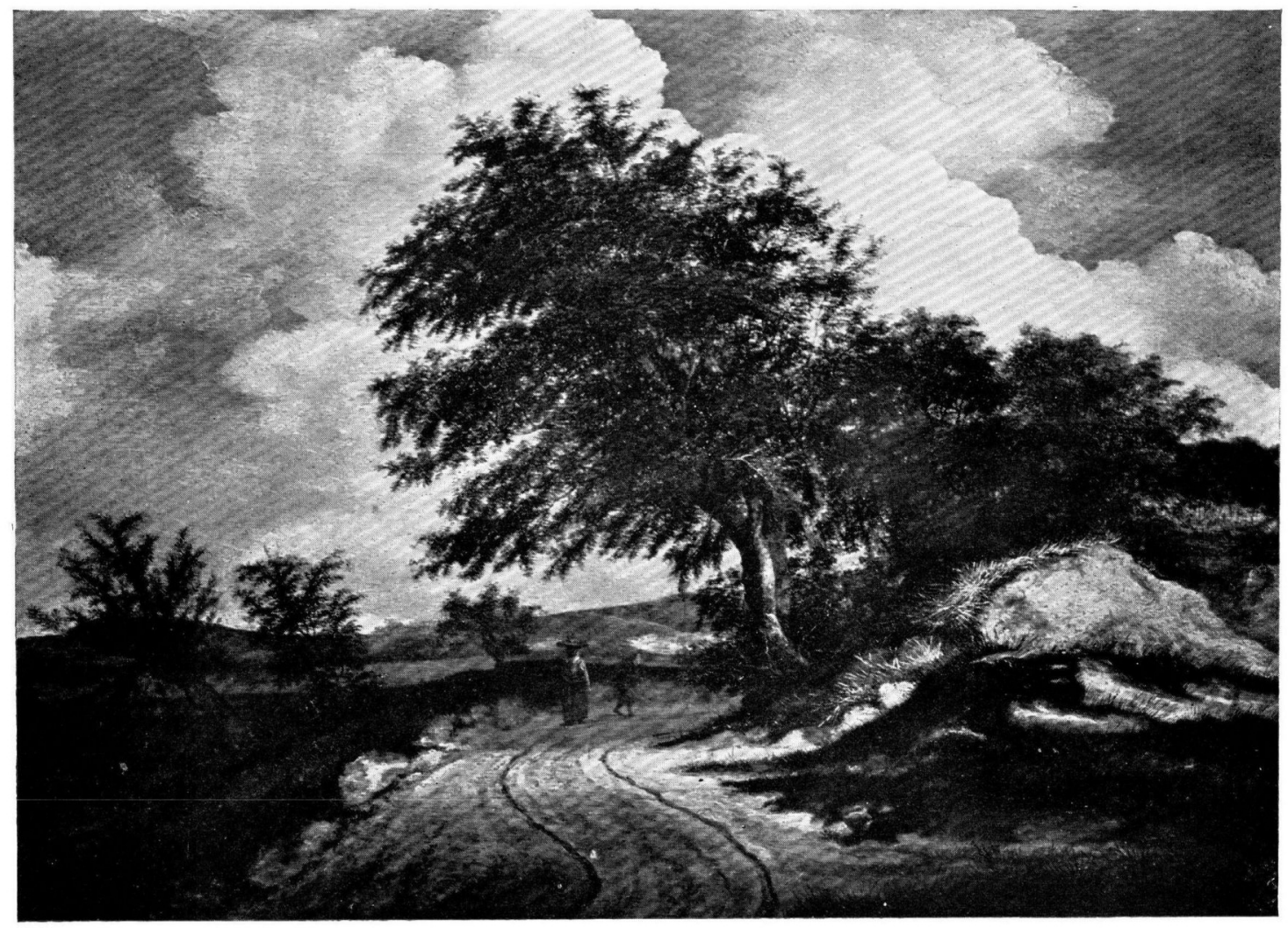

GODAR' Kanper. Iandschap.

(Mc W. Aliralianis, Londen).

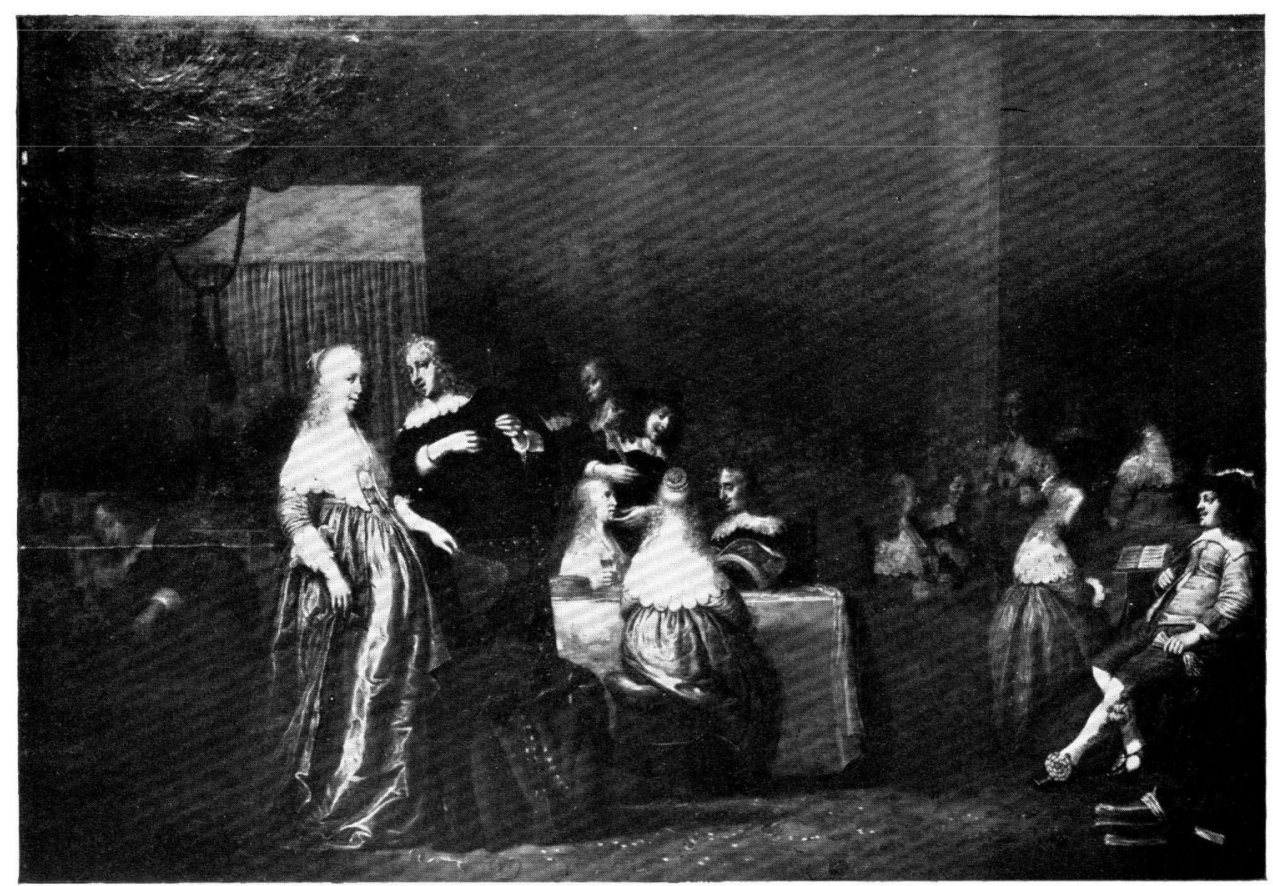

Gomart Kamper. Gezelschap.

(n den Kunsthandel 
Onder de souvenirs, die hij achterlaat, zijn een penning met Hendrick de Vierde, silveren lepelen, een gouden ring met een saphier enz.

5 November 1679 wijzigt hij dit testament nog in enkele punten ${ }^{\mathbf{l}}$ - - Wij zagen reeds dat hij 13 dagen later begraven werd.

ro Febr. 1680. Acte over rentebrieven enz., voor Doctor FloRentius CAmper en Johannes Camper, executeurs over den Testamente van Goddartus Camper. Nu schrijft de Notaris D. Camper, die de Acte opmaakt met een C, de anderen met K.! 2) erfenis.

Bij Not. N. VAN LEeUwen vindt men nog acten over de verdeeling der

Over zijn verblijf te Naarden zij nog vermeld, dat hij 22 Dec, r668 daar het burgerrecht kocht en 26 Jan. 1669 tot Schepen werd voorgedragen en ook verkozen. In $167 \mathrm{I}$ trad hij als zoodanig af. 1672 werd hij potmeester (arm-meester) en verliet in dat jaar Naarden weder.

Onze afbeelding van een oude, niet fraaie dame, toont wat KAMPER als portretschilder vermocht. Het bevindt zich in 's Rijks Museum en is gemerkt:

$$
\begin{gathered}
A^{0}{ }_{1} 65^{6} \\
\text { Aet } 60 \\
\text { CKamper fe. }
\end{gathered}
$$

Zijn fraaiste werk is wel het landschap dat tevens hier afgebeeld is, in het bezit van den Heer Walter Abraham te Londen. Thans duidelijk G. Kamper $f$ gemerkt droeg het vroeger, toen het nog zeer rijkelijk overschilderd was in HOBBEMA's stijl, diens valsche handteekening.

Te Leiden zal men weldra een familiegroep kunuen zien, door Utrecht in bruikleen gegeven : de ouders met een kind in een landschap, de man, nog al raar, in romeinsch kostuum. Het is groot: $1.89 \times 2.26$. Voluit gemerkt en 1659 gedateerd. Het is wat bont van kleur en niet zijn beste werk. Zonder twijfel zal men nog wel meer schilderijen van hem vinden.

Reeds 1647 bezat de Heer CoRNelis vaN DER TIN, in zijn leven Schepen van Haarlem: een principaal van CAMPER.

Ik vind nog de beschrijving naar een photographie van een bordeelscene gem: G. Kamper ${ }_{1638}$, wellicht het stuk nu in het Museum te Danzig. Op den voorgrond 19 figuren, op den $2^{\text {en }}$ grond 6 in een nevenvertrek. Links een paar, hand aan hand, staande. Rechts wordt gevrijd op allerhande manieren. Een heer speelt op de fluit, terwijl een dame hem de muziek voorhoudt. Heel rechts drie

1) Prot. Not. R. CocQurs, Leiden.

2) $\gg$ N. Van Leeuwen, Leiden. 
figuren op een verhevenheid. In het midden maken twee dames het één heer lastig. Links ziet men door een raam in een tuin. Achter het gezelschap twee tapijten met landschappen $48 \times 63 \mathrm{cM}$.

In den boedel van de Wede van Mr. JOHAN VAN DER BURGH te 's-Gravenhage, I74I, bevond zich een groot kabinet van schilderijen waarin:

Petrus, geschilderd door JAN LIEvens en Christus aan den geeselpaal door G. KAMPER.

Wij mogen GODART KAMPER dus rangschikken onder de veelzijdige schilders uit den bloeitijd onzer schilderkunst, die vooral als landschapschilder uitmuntend werk heeft nagelaten (hoevele landschappen van hem zijn wellicht nog te zoeken onder ,onbekenden", door het verwijderen van zijn handteekening?) en die het niet verdiende geheel aan de vergetelheid overgeleverd te worden.

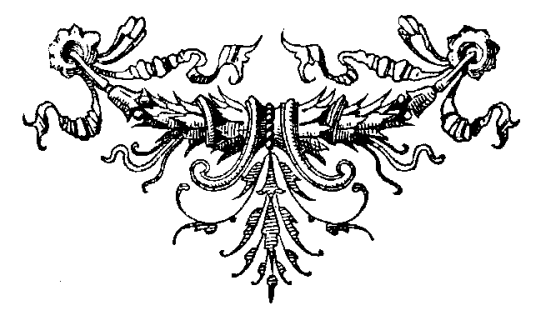

